\title{
ПОИСК ГЕНОВ-МИШЕНЕЙ \\ С ПОМОЩЬЮ РЕКОНСТРУКЦИИ ГЕННЫХ СЕТЕЙ НА ПРИМЕРЕ БОЛЕЗНИ ПАРКИНСОНА
}

\author{
Ю.Л. Орлов ${ }^{1}$, Э.Р. Галиева ${ }^{2}$, А.И. Дергилев², Н.Г. Орлова ${ }^{3}$
}

${ }^{1}$ Институт цифровой медицины, Первый МГМУ им. И.М. Сеченова (Сеченовский Университет), 119991, Россия, Москва, Большая Пироговская, 2-4.

${ }^{2}$ Новосибирский государственный университет, 630090, Россия, Новосибирск, Пирогова, 2.

${ }^{3}$ Финансовый университет при Правительстве РФ, 125993, Россия, Москва, Ленинградский просп., 49.

DOI: 10.19163/MedChemRussia2021-2021-169

E-mail:orlov@d-health.institute

Реконструкция регуляторных генных сетей на основе данных об экспрессии генов, белок-белковых взаимодействиях, функциональной аннотации с помощью методов биоинформатики позволяет строить модели заболеваний, что важно для определения эффективности диагностики и терапии, возможности направленного лекарственного воздействия на гены-мишени. Активный исследовательский интерес к изучению болезни Паркинсона связан с медицинской и экономической значимостью проблемы [1]. Для поиска новых мишеней терапии необходим анализ генной сети (белок-белковых взаимодействий) для исследуемого заболевания, определение кластеров в сети, выявление ключевых генов, обладающих наибольшим числом контактов.

С помощью онлайн-инструментов биоинформатики [2] OMIM, PANTHER, g:Profiler, GeneMANIA и STRING-DB мы проанализировали актуальный на данный момент массив данных, связанных с болезнью Паркинсона, рассчитали категории генных онтологий для большого списка генов, визуализировали их и построили генные сети, содержащие выявленные ключевые объекты и их взаимосвязи. Среди узловых генов сети найдены SNCA, CASP3, GFRA1, HTT, PARK7, что подтверждается актуальными ассоциаций генов-кандидатов. Генетические варианты в LRRK2 связаны с большинством всех известных наследуемых проявлений болезни Паркинсона.

На примере данного заболевания отработана методика реконструкции генных сетей для комплексных заболеваний. Анализ генов, связанных с болезнью Паркинсона, определение их положения в генной сети (связанности) позволяет оценить их перспективность в качестве генов-мишеней для лекарственных воздействий.

\section{Литература}

[1] D.G. Hernandez, X. Reed, and A.B. Singleton, J. Neurochem., 2016, 139(Suppl 1), 59-74, DOI: 10.1111/jnc.13593.

[2] J.S. Amberger, C.A. Bocchini, A.F. Scott, A. Hamosh, Nucleic Acids Res., 2019, 47(D1), 1038-1043, DOI:10.1093/nar/gky1151.

$$
-169-
$$

